\title{
Is Tayside becoming a Scottish hotspot for Lyme borreliosis?
}

\author{
${ }^{1}$ GS Slack, ${ }^{2} \mathrm{~S}$ Mavin, ${ }^{3} \mathrm{D}$ Yirrell, ${ }^{4} \mathrm{DO}$ Ho-Yen \\ ${ }^{1}$ Trainee Clinical Scientist, Medical Microbiology Department, Ninewells Hospital \& Medical School, Dundee; ${ }^{2}$ Clinical Scientist, National Lyme \\ Borreliosis Testing Laboratory, Microbiology Department, Raigmore Hospital, Inverness; ${ }^{3}$ Consultant Clinical Scientist, Medical Microbiology \\ Department, Ninewells Hospital \& Medical School, Dundee; ${ }^{4}$ Head of Microbiology Department, Raigmore Hospital, Inverness, UK
}

\begin{abstract}
The epidemiology of Lyme borreliosis (LB) in Tayside was studied and compared with Highland (an area of high endemicity) and the rest of Scotland. From April 200I to March 2008 the incidence of LB in Tayside rose from an estimated 2.57 to 5.84 per 100,000 population. In 2008/09 the incidence of LB in Tayside increased further to an estimated 13.85 per 100,000 population. This rise was significant and, although numerically less than that in Highland (37.24 to 49.69 per 100,000 population), it was proportionally much larger (I37\% vs $33 \%$ ) and confirmed that LB in Tayside has diverged from that in non-endemic Scottish regions. The dramatic rise of LB in Tayside cannot be accounted for by changes in laboratory protocol or changes in the number or demographics of patients tested. However, changes in climatic conditions and alterations in clinical presentations may have contributed to this significant rise.
\end{abstract}

KEYWORDS Lyme borreliosis, Borrelia burgdorferi, Scotland, Tayside

DECLARATION OF INTERESTS No conflict of interests declared.

\section{INTRODUCTION}

Lyme borreliosis (LB) is the most common vector-borne disease in Europe and the USA.' The causative agent, spirochaete Borrelia burgdorferi sensu lato, can be differentiated into at least 15 genospecies, seven of which are known to cause human disease. ${ }^{2}$ The spirochaete is transmitted between vertebrate hosts by ixodid ticks as they take a blood meal. In Scotland the vector for LB is Ixodes ricinus, or sheep tick, which feeds on a range of mammals including birds, deer and sheep. ${ }^{3}$ The majority of human cases occur in the summer months as human behaviour increases the risk of exposure and tick nymphs are questing. ${ }^{4}$ Nymphs are much smaller than their adult counterparts and often go unnoticed, facilitating the transmission of the organism which requires the tick to have fed for 24-48 hours before transmission can occur.

The incidence of LB has been rising across the world, with foci of infection in the USA, Asia and Europe.' Rises in LB have been linked with improved diagnostics, raised awareness, changes in land use, increased tick density and burden of tick disease. ${ }^{5}$ In Scotland the incidence of LB is highest in the Highlands, an area of high endemicity. ${ }^{6}$ Scottish studies have therefore focused on this region and there is little information on the incidence and epidemiology of LB in other regions. There have been anecdotal reports that Tayside has experienced an increase in test requests for $L B$, and that an increased number of samples have been referred to the National LB Testing Laboratory (NLBTL) in recent years. This study was therefore carried out to identify any significant changes in the incidence of LB in Tayside.

\section{MATERIALS AND METHODS \\ Patients' details}

Samples submitted to the Medical Microbiology Department at Ninewells Hospital \& Medical School in Dundee, representing infection in Tayside, and samples submitted to the NLBTL, Raigmore Hospital, Inverness, representing infection in Highland and the rest of Scotland, were studied. Archived data on patients' age, sex, month of sample submission, test request details and test results were collected and analysed for samples submitted from Tayside for B. burgdorferi testing from April 200I to March 2010. Data were extracted from the local laboratory's computing system, LabCentre, and analysed in Excel. Archived data on samples submitted from Highland and the rest of Scotland for B. burgdorferi testing from April 2004 to March 2010 were extracted from the NLBTL computing system, Medipath, and analysed in Excel.

Tayside and Highland refer to health boards in Scotland. Tayside covers the city of Dundee and the counties of Angus and Perth \& Kinross. Highland extends from Argyll \& Bute in the south to Caithness and Sutherland in the north. The rest of Scotland refers to all other health boards in Scotland with the exception of Grampian.

\section{Laboratory tests}

Throughout the study period, the two-step approach to laboratory testing was adopted in both centres. ${ }^{7}$ Samples were screened locally using a $B$. burgdorferi immunoglobulin (IgM/lgG) enzyme-linked immunoassay (EIA) (Zeus Scientific) according to the manufacturer's instructions. Confirmatory testing of EIA equivocal/ reactive samples was carried out by the NLBTL with an 
TABLE I Number of patients tested and new cases of Lyme borreliosis for Tayside and Highland from April 200I to March 2010

\begin{tabular}{|c|c|c|}
\hline Year (Apr-Mar) & Patients tested & New cases \\
\hline \multicolumn{3}{|l|}{ Tayside } \\
\hline $2001 / 02$ & 505 & $10(1.98 \%)$ \\
\hline $2002 / 03$ & 547 & $8(1.46 \%)$ \\
\hline $2003 / 04$ & 691 & $9(1.30 \%)$ \\
\hline $2004 / 05$ & 630 & $5(0.79 \%)$ \\
\hline $2005 / 06$ & 606 & $9(1.49 \%)$ \\
\hline $2006 / 07$ & 736 & $24(3.26 \%)$ \\
\hline $2007 / 08$ & 749 & $23(3.07 \%)$ \\
\hline $2008 / 09$ & 780 & 55 (7.05\%) \\
\hline $2009 / 10$ & 881 & $67(7.60 \%)$ \\
\hline \multicolumn{3}{|l|}{ Highland } \\
\hline $2004 / 05$ & $\mathrm{n} / \mathrm{a}$ & 56 \\
\hline $2005 / 06$ & 1,072 & 61 (5.69\%) \\
\hline $2006 / 07$ & 1,165 & $78(6.70 \%)$ \\
\hline $2007 / 08$ & 1,052 & 115 (10.93\%) \\
\hline $2008 / 09$ & 1,069 & $154(14.41 \%)$ \\
\hline $2009 / 10$ & 1,202 & 175 (I4.56\%) \\
\hline
\end{tabular}

in-house lgGWestern blot. Enzyme-linked immunoassaynegative samples with strong clinical suspicion of LB were also submitted for Western blot testing. The Western blot was performed as previously described. ${ }^{8}$ However, the antigen used and interpretation criteria were revised in April 2004,9 June $2007^{10}$ and October $2008 .{ }^{5}$ In this study, all patients with a weak positive or positive Western blot result were classed as seropositive.

To further investigate LB in Tayside, patient demographics and test request details for samples submitted between March 2006 and April 2010 were studied. To improve sample size, data from 2006/07 were combined with $2007 / 08$, and data from $2008 / 09$ combined with $2009 / 10$. There was good correlation in the age/sex structure of patients tested and no significant differences in the number of new cases in the combined study years.

Meteorological Office data on monthly rainfall for the north of Scotland (Highland) and east of Scotland (Grampian, Tayside, Perthshire, Fife, Lothian and Borders) were sourced from the Meteorological Office website." Data were analysed for differences between areas and years and significance determined using the chi-squared $\left(\chi^{2}\right)$ test. Mid-year population estimates were gathered from the General Register Office for Scotland. ${ }^{2}$

\section{RESULTS}

In Tayside there has been a significant rise in the number of patients tested for LB rising from 505 in 2001/02 to 881 in $2009 / 10 \quad\left(\chi^{2}=168.6, \quad p<0.001\right)$ (Table I). The incidence of LB in Tayside has also significantly risen in this

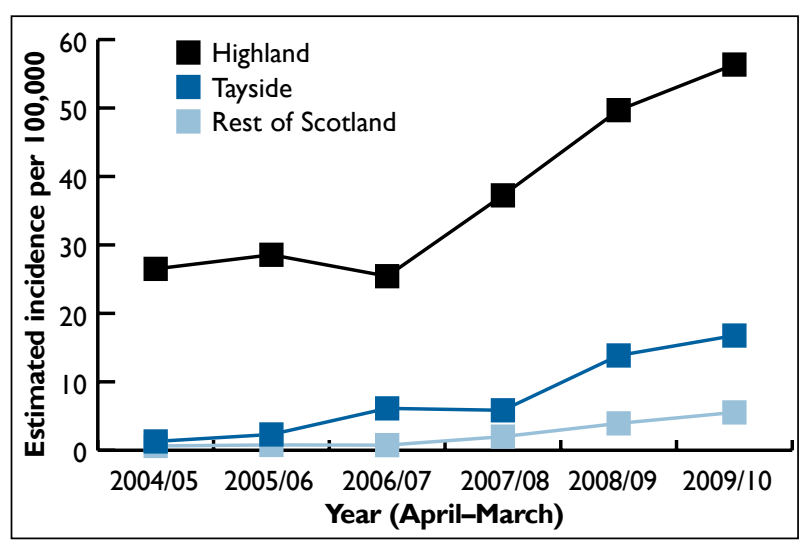

FIGURE I Incidence of Lyme borreliosis for Tayside, Highland and rest of Scotland from April 2004 to March 2010.

time, from an estimated $2.57 / 100,000$ population in $2001 / 02$ to $16.76 / 100,000$ population in $2009 / 10\left(\chi^{2}=42.1\right.$, $\mathrm{p}<0.00 \mathrm{I}$ ) (Figure I). This rise can be attributed to significant increases in the number of cases of LB in $2006 / 07\left(\chi^{2}=6.8, p<0.01\right)$ and 2008/09 $\left(\chi^{2}=13.1, p<0.001\right)$ (Table I). Despite fluctuations in the number of patients tested in recent years (Table I), the estimated incidence of LB in Highland has risen significantly each year since $2006 / 07$, rising from $25.43 / 100,000$ population in $2006 / 07$ to $56.35 / 100,000$ population in $2009 / 10$ ( $\left.\chi^{2}=36.0, p<0.00 I\right)$ (Figure I). In comparison, incidence for the rest of Scotland remained very low at 0.78 and $0.75 / 100,000$ population in $2005 / 06$ and $2006 / 07$, rising steadily to $5.53 / 100,000$ population in 2009/10 (Figure I).

\section{Tayside patient demographics}

There were no significant differences in the proportion of male and female patients tested in Tayside in 2006/08 (49.2\% male, $50.8 \%$ female) and 2008/10 (47.5\% male, $52.5 \%$ female). Moreover, there was good correlation between the age/sex structure of patients tested in Tayside in 2006/08 with those tested in 2008/10 $\left(r^{2}=0.95 / 0.83\right.$ for males/females respectively). Additionally, the ratio of male to female LB cases in Tayside did not change significantly, with 27 male (57.4\%) and 20 female $(42.6 \%)$ cases in $2006 / 08$ and 61 male $(50.0 \%)$ and 61 female $(50.0 \%)$ cases in $2008 / 10$. There were also no significant differences in the proportion of cases in patients aged less than 40 years, 40-64 years or over 64 years in 2006/08 versus $2008 / 10$, with the majority of cases in those of working age.

\section{Clinical category}

In 2008/I0, a significantly reduced proportion of LB cases in Tayside had clinical details suggestive of early LB $\left(\chi^{2}=11.7, p<0.00 I\right)$ (Table 2). There was also a significant rise in the proportion of cases with neurological or joint symptoms, from five (10.6\%) in $2006 / 08$ to $37(30.3 \%)$ in $2008 / 10\left(\chi^{2}=7.0, p<0.01\right)$. A rise in the proportion of cases with clinical details classified as 'other' in 2008/10 was not significant. 
TABLE 2 Clinical classification of test request details for Tayside cases of Lyme borreliosis

\begin{tabular}{|l|l|l|}
\hline Test request details & $\mathbf{2 0 0 6 / 0 8}$ & $\mathbf{2 0 0 8 / 1 0}$ \\
\hline Early Lyme borreliosis & $39(83.0 \%)$ & $70(57.4 \%)$ \\
\hline Neurological & $5(10.6 \%)$ & $31(25.4 \%)$ \\
\hline Joint symptoms & 0 & $6(4.9 \%)$ \\
\hline Other & $2(4.3 \%)$ & $6(4.9 \%)$ \\
\hline Not stated & $\mathrm{I}(2.1 \%)$ & $9(7.4 \%)$ \\
\hline Total & 47 & 122 \\
\hline
\end{tabular}

"Includes erythema migrans/rash/tick bite/flu-like illness.

\section{Weather data}

Weather data for the north and east of Scotland from 2006 to 2009 were analysed. The east of Scotland had a significant rise in average monthly rainfall in JanuaryMarch $2007\left(\chi^{2}=5.4, p<0.025\right)$. This was followed by a smaller rise in 2008 and a significant fall in $2009\left(\chi^{2}=14.2\right.$, $\mathrm{P}<0.00 \mathrm{I}$ ) (Figure 2A). This pattern was mirrored in the north of Scotland, which also had a significant rise in average monthly rainfall in January-March $2007\left(\chi^{2}=23.02\right.$, $\mathrm{p}<0.00 \mathrm{I})$, followed by a smaller rise in 2008 and a significant fall in $2009\left(\chi^{2}=10.4, p<0.002\right)$ (Figure 2B).

In the east of Scotland May-July 2007 and 2009 were significantly wetter than the same period in 2006 $\left(\chi^{2}=17.39, p<0.001\right.$ and $\chi^{2}=9.70, p<0.002$, respectively $)$ or $2008\left(\chi^{2}=11.73, \mathrm{p}<0.001\right.$ and $\chi^{2}=5.56, \mathrm{p}<0.02$, respectively) (Figure 2A). May-July 2007 was also significantly wetter in the north of Scotland than in 2006 or $2008\left(\chi^{2}=4.63, \mathrm{p}<0.05 ; \chi^{2}=14.79, \mathrm{p}<0.001\right.$; and $\chi^{2}=9.48, \mathrm{p}<0.003$ respectively). In 2009 May-July was significantly wetter than 2008 but not 2006 (Figure 2B).

\section{DISCUSSION}

There has been an increasing rise in LB in Tayside. From April 200I to March 2006 there were up to ten new cases of LB confirmed in Tayside each year (Table I). However, in $2006 / 07$ this rose significantly to $24\left(\chi^{2}=6.8\right.$, $\mathrm{P}<0.0 \mathrm{I})$ and the estimated incidence of LB in Tayside was significantly higher than that for the rest of Scotland, excluding Highland (6.12 vs $0.75 / 100,000, \chi^{2}=83.2$, $\mathrm{p}<0.00 \mathrm{I}$ ) (Figure $\mathrm{I}$ ). This rise was maintained and in 2008/09 the incidence of LB in Tayside increased significantly to $13.85 / 100,000$ population $\left(\chi^{2}=36.13\right.$, $\mathrm{p}<0.00 \mathrm{I})$. Although this rise was numerically lower than that seen in the endemic region of Highland, it was proportionally much greater ( $137 \%$ vs $33.4 \%)$ and confirmed that the incidence of LB in Tayside is diverging from the rest of Scotland, excluding Highland (Figure I).

There has also been a significant increase in testing in Tayside (Table I), demonstrating the increased awareness of the general and medical population of Tayside. However, as there was a significant increase in the proportion of

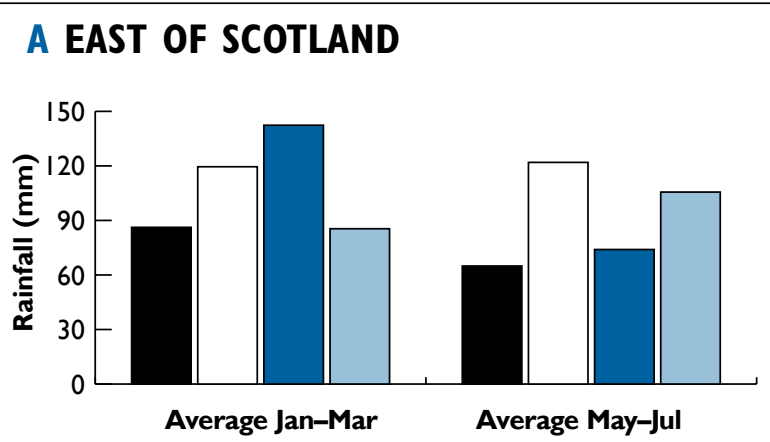

\section{B NORTH OF SCOTLAND}

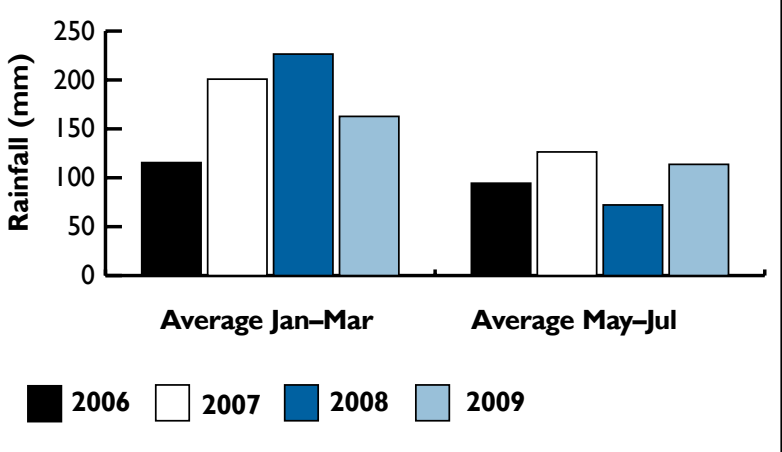

FIGURE 2 Average monthly rainfall for January-March and May-July in the east (A) and north (B) of Scotland.

patients that were positive in 2006/07 (9/606 vs 24/736, $p=0.0499$, Fisher's exact test) and again in 2008/09 ( $23 / 749$ vs $55 / 780 p=0.0004$, Fisher's exact test), this suggests that the rise of LB in Tayside cannot be accounted for by increased testing. There were also no significant changes in the demographics of patients tested or of LB cases, despite the proportion of male LB cases declining from $57.4 \%$ in $2006 / 08$ to $50 \%$ in $2008 / 10$.

Scotland appears unusual in having more male than female cases as a large number of European countries, including Germany and Portugal, report a female preponderance. ${ }^{13,14}$ Age distribution of LB can also vary between studies. Some show a bimodal distribution with a peak of cases in five-15 year-olds and a peak in the older age group. ${ }^{13,15,16}$ However, reports from Scotland show a broad peak in those of working age. ${ }^{6,17}$ This corresponds to that seen in this study, where the majority of cases occurred in 30-64 year-olds, with very few cases in patients aged less than 25 or over 70 years.

Although there were no significant changes in the demographics of $L B$ cases in Tayside, there was a significant rise in the proportion of LB cases with neurological or joint symptoms recorded on test request forms in 2008/I0 compared with 2006/08 (Table 2).

There was also a rise in the number of cases with test request details classified as 'other', indicating that the clinical pattern of LB in Tayside is changing, with a more diverse spectrum of symptoms than previously seen. We 
speculate this may be linked to a change in B. burgdorferi genospecies within the local tick population as certain genospecies are associated with differing clinical presentations. For example, B. afzelii has been associated with acrodermatitis chronica atrophicans, while $B$. burgdorferi sensu stricto is strongly associated with arthritic symptoms and B. garinii with neurological presentations. ${ }^{18,19}$ However, there is little information on the prevalence and distribution of $B$. burgdorferi genospecies in the UK. A small study sampling two sites in the Scottish Highlands isolated B. afzelii and B. burgdorferi sensu stricto, while other UK studies have isolated $B$. garinii and $B$. valaisiana. ${ }^{20-22}$ Changes in the distribution of $B$. burgdorferi genospecies may therefore have led to a change in the clinical presentation of LB in Tayside, but this may not explain the dramatic and sustained rise of LB in $2008 / 10$.

Tick population densities are influenced by a number of interconnected factors, including host availability, habitat and climate conditions. It has been reported that a wet January-March may aid tick survival and that there is an association between tick establishment and LB endemicity in ticks. ${ }^{4,23}$ Moreover, it has been reported that infection rates in ticks correlate with disease frequency in humans..$^{23}$ In the east of Scotland, January-March rainfall peaked in 2008, coinciding with the dramatic rise of LB

\section{REFERENCES}

I Steere AC. Borrelia burgdorferi (Lyme disease, Lyme borreliosis). In: Mandell GL, Bennett JE, Dolin R, editors. Mandell, Douglas, and Bennett's principles and practice of infectious diseases. 7th ed. New York: Churchill Livingstone Elsevier; 2009. p. 307I-8I.

2 Gern L, Douet V, Lopez Z et al. Diversity of Borrelia genospecies in Ixodes ricinus ticks in a Lyme borreliosis endemic area in Switzerland identified by using new probes for reverse line blotting. Ticks Tick Borne Dis 2010; I: 23-9. doi:10.1016/j.ttbdis.2009.II.001

3 Cutler SJ, Woodward MJ. Lyme borreliosis in the UK - ecology and risks to domestic animals and man. Rev Med Microbiol 200I; 12:199-209.

4 Mavin S, Joss AWL, Ho-Yen DO. Incidence of Scottish Lyme disease appears to be related to the effects of weather on tick survival and human behaviour. J R Coll Physicians Edinb 2005; 35: I I2-5.

5 Mavin S, Evans R, Milner RM et al. Local Borrelia burgdorferi sensu stricto and Borrelia afzelii strains in a single mixed antigen improves western blot sensitivity. J Clin Pathol 2009; 62:552-4. doi:I0.I I36/jcp.2008.06346 I

6 Milner RM, Mavin S, Ho-Yen DO. Lyme borreliosis in Scotland during two peak periods. J R Coll Physicians Edinb 2009; 39:196-9.

7 Centers for Disease Control and Prevention. Recommendations for test performance and interpretation from the 2nd National Conference on serologic diagnosis of Lyme disease. MMWR Morb Mortal Wkly Rep 1995; 44:590-I.

8 Davidson MM, Chisholm SM, Wiseman AD et al. Improved serodiagnosis of Lyme Disease. J Clin Pathol Mol Pathol 1996; 49: M80-4. doi:I0.I I36/mp.49.2.M80

9 Evans R, Mavin S, Ho-Yen DO. Audit of the laboratory diagnosis of Lyme disease in Scotland. J Med Microbiol 2005; 54: II39-4I. doi: I0.1099/jmm.0.46003-0

10 Mavin S, Milner RM, Evans R et al.The use of local isolates in Western blots improves serological diagnosis of Lyme disease in Scotland. J Med Microbiol 2007; 56:47-5I. doi: I0.1099/jmm.0.46793-0

I I Met Office. UK climate and weather statistics. Available from: http://www.metoffice.gov.uk/climate/uk in Tayside (Figure 2A). That year also had a dry summer, potentially leading to increased human exposure. However, winter rainfall fell in 2009, which also had a wet summer; yet the incidence of LB in Tayside remained high in 2009/10. Moreover, a similar rainfall pattern was observed in the north of Scotland (Figure 2B) and, although a significant rise of $L B$ was detected in Highland in 2008/09, this rise was of a similar size to the previous year, suggesting rainfall pattern alone cannot account for the rise of LB in Tayside (Table I).

When LB in Scotland has been examined, Highland has consistently been shown to be an endemic region. However, this study has shown that the incidence of LB in Tayside is also rising. Medical practitioners should therefore be aware of the increased risk to patients who visit or reside in these areas and the wide spectrum of clinical symptoms associated with LB. It appears that Tayside is in the early stages of becoming a 'hot spot' for $L B$, diverging from the pattern seen in the rest of Scotland and developing into an area of endemicity similar to Highland.

Acknowledgements We would like to thank the users of our service for their helpful co-operation, NHS Education for Scotland for supporting the Trainee Clinical Scientist scheme, the medical microbiology staff in Highland and Tayside for their support and Ross Martin for his IT assistance.

12 General Register Office for Scotland. Mid-year population estimates. Available from: http://www.gro-scotland.gov.uk/ statistics/theme/population/estimates/mid-year/index.html

13 Mehnert WH, Krause G. Surveillance of Lyme borreliosis in Germany, 2002 and 2003. Euro Surveill 2005; 10: 83-5.

14 Lopes de Carvalho I, Núncio MS. Laboratory diagnosis of Lyme borreliosis at the Portuguese National Institute of Health (19902004). Euro Surveill 2006; II:257-60.

15 Centers for Disease Prevention and Control (CDC). Lyme disease - United States 2003-2005. MMWR Morb MortalWkly Rep 2007; 56:573-6.

16 Christova I, Komitova R. Clinical and epidemiological features of Lyme borreliosis in Bulgaria. Wien Klin Wochenschr 2004; I 16:42-6. doi:10.1007/BF03040423

17 Milner RM, Mavin S, Ho-Yen DO. Lyme borreliosis in Scotland is different. J Infect 2009; 59:146-7. doi:10.1016/j.jinf.2009.05.007

18 Balmelli T, Piffaretti JC. Association between different clinical manifestations of Lyme disease and different species of Borrelia burgdorferi sensu lato. Res Microbiol 1995; 16:329-40. doi:10.1016/0923-2508(96)81056-4

19 Van Dam AP, Kuiper H,Vos K et al. Different genospecies of Borrelia burgdorferi are associated with distinct clinical manifestations of Lyme borreliosis. Clin Infect Dis 1993; 17:708-17.

20 Davidson MM, Evans R, Ling $\mathrm{CL}$ et al. Isolation of Borrelia burgdorferi from ticks in the Highlands of Scotland.J Med Microbiol 1999; 48:59-65. doi:10.1099/002226I5-48-I-59

21 Ling CL, Joss AWL, Davidson MM et al. Identification of different Borrelia burgdorferi genomic groups from Scottish ticks.J Clin Pathol Mol Pathol 2000; 53:94-8. doi: I0.1 I36/mp.53.2.94

22 Robertson JN, Gray JS, Stewart P. Tick bite and Lyme borreliosis risk at a recreational site in England. Eur J Epidemiol 2000; 16:64752. doi:10.1023/A:1007615109273

23 Walk ST, Xu G, Stull JW et al. Correlation between tick density and pathogen endemicity, New Hampshire. Emerg Infect Dis 2009; 15:585-7. doi:I0.320I/eid I504.080940 